\title{
A importância do trabalho do Assistente Social na implementação do Consultório de Rua na cidade de Rio Grande - RS
}

\author{
La importancia del trabajo del trabajador social en la implementación de \\ la Clínica Callejera en la ciudad de Río Grande - RS
The importance of the work of the Social Worker in the implementation of the Street Clinic in the city of Rio Grande - RS

\author{
Esp. Ivania de Farias Silveira Siqueira ${ }^{1}$ \\ Me. Marcel Jardim Amaral ${ }^{2}$ \\ Dr. Vilmar Alves Pereira ${ }^{3}$
}

\begin{abstract}
Resumo
O presente trabalho aborda o contexto da implementação de consultórios de rua no Brasil, mostrando sua importância no atendimento de pessoas em situação de rua e tendo como objetivo principal enfatizar o papel do assistente social para seu funcionamento. Além disso, através do histórico dos consultórios de rua em outras cidades, busca-se mostrar o quão importante seria a implantação desse projeto na cidade do Rio Grande e o quanto se faz necessária a atuação do assistente social para haver sucesso na execução dos propósitos de tal projeto. Embasado em alguns textos sobre o assunto e nas experiências já vivenciadas em outras cidades, o trabalho baseia-se em metodologia explanatória com o intuito de enfatizar a relação do projeto de consultórios de rua e o papel do profissional do Serviço Social, trazendo uma breve explicação sobre a função do agente de Serviço Social e o histórico do projeto de consultórios de rua em suas primeiras experimentações. Por final, aponta a situação atual da cidade de Rio Grande acerca da população de rua e como a implantação de um consultório de rua poderia ajudar na redução de danos causados pelas condições de vida destes cidadãos.
\end{abstract}

Palavras-chave: Consultório; População; Rua; Serviço Social.

\section{Resumen}

El presente trabajo aborda el contexto de la implementación de oficinas en la calle en Brasil, mostrando su importancia en el cuidado de las personas en la calle y con el objetivo principal de enfatizar el papel del trabajador social para su funcionamiento. Además, a través de la historia de las oficinas en las calles de otras ciudades, buscamos mostrar cuán importante sería la implementación de este proyecto en la ciudad de Río Grande, y cuánto es necesario el trabajo del trabajador social para tener éxito en la realización de los propósitos. de tal proyecto. Basado en algunos textos sobre el tema y en las experiencias ya vividas en otras ciudades, el trabajo se basa en una metodología explicativa, con el fin de enfatizar la relación entre el diseño de las oficinas de la calle y el papel del profesional del Servicio Social, presentando un breve explicación del papel del agente del Servicio Social y la historia del diseño de oficinas en la calle en sus primeros experimentos. Y finalmente, señala la situación actual de la ciudad de Río Grande con respecto a la población de la calle, y cómo la

\footnotetext{
${ }^{1}$ Especialista em Estratégia Saúde da Família pelo Instituto Educar Brasil; Associação Casa Lar; Rio Grande; Rio Grande do Sul; Brasil; ivania.silveira@bol.com.br.

2 Doutorando pelo Programa de Pós-Graduação em Educação Ambiental (PPGEA/FURG); Fundação Universidade Federal do Rio Grande; Rio Grande; Rio Grande do Sul; Brasil; amaral.marcel@yahoo.com.

${ }^{3}$ Doutor pelo Programa de Pós-Graduação em Educação (PPGEdu/UFRGS); Rio Grande; Rio Grande do Sul; Brasil; vilmar1972@gmail.com.
} 
implementación de una oficina de la calle podría ayudar a reducir el daño causado por las condiciones de vida de estos ciudadanos.

Palabras clave: Oficina; Población; Calle; Trabajo Social.

\begin{abstract}
This paper discusses the context of the implementation of street offices in Brazil, showing its importance in the care of people on the streets, and with the main objective to emphasize the role of social worker for its operation. In addition, through the history of street offices in other cities, we seek to show how important was the implementation of this project in Rio Grande, and how much is necessary the action of the social worker to be successful in carrying out the purposes in such a project, based on some texts on the subject and experiences already lived in other cities, the work were based on explanatory methodology, in order to emphasize the street offices project relationship and the role of professional social work, bringing a brief explanation the role of the social service agent, and the history of street offices project in its first trials. And by the end, says the current situation of the city of Rio Grande about the homeless population, and as the implementation of a street office could help in reducing damage caused by the living conditions of street people.
\end{abstract}

Keywords: Office; People; Street; Social Service.

\title{
1. Introdução ${ }^{4}$
}

Tendo por foco a necessidade da implantação de um consultório de rua na cidade do Rio Grande - RS, o presente artigo tem como objetivo principal enfatizar a importância do papel do profissional de Serviço Social na eficácia do atendimento junto à população em situação de rua da cidade, apontando locais e situações que necessitam da intervenção de dispositivos de cuidado à saúde. O trabalho ainda visa debater como e quando o profissional se faz indispensável dentro do projeto, tendo papel ativo na busca do cumprimento dos direitos dos cidadãos de rua, ajudando a promover a redução de danos à saúde dessas pessoas e a ampliar o acesso e a qualidade da atenção integral às mesmas.

No que concerne a metodologia, trata-se exclusivamente de um estudo explanatório embasado em textos de estudiosos na área de Serviço Social e da Educação, uma vez que o tema ainda é foco de poucos estudos e sobre o qual ainda existem muitas dúvidas. Como referenciais teóricos, foram utilizados alguns artigos que falam sobre o tema e cartilhas da Política Nacional, bem como o Código de Ética do Assistente Social e bibliografias que abordam o tema.

Para entender a situação do acesso à saúde por parte do grupo em análise, se faz necessário verificar como está configurado o ingresso dessa população nos serviços básicos de saúde e discutir de que forma o assistente social pode contribuir no atendimento as pessoas em situação de rua com base em articulação com a rede intersetorial. Tendo em vista mostrar a importância de tal dispositivo atendendo na cidade de Rio Grande- RS, o trabalho aqui

\footnotetext{
4 "O presente trabalho foi realizado com apoio da Coordenação de Aperfeiçoamento de Pessoal de Nível Superior - Brasil (CAPES) - Código de Financiamento 001".
} 
apresentado discorre acerca dessa nova modalidade de atendimento à população, além de apontar as doenças que mais acometem a população de rua. Além disso, apresenta-se a experiência com a implementação de consultórios de rua em outras cidades, seus resultados e como tal dispositivo poderia ser eficaz para com a população de rua da cidade de Rio Grande - RS, cuja situação atual também se faz presente ao final do trabalho.

A área da saúde é um importante espaço em que a intervenção do profissional de Serviço Social é de vital importância, pois o mesmo possui ferramentas para reinseri-los socialmente através de projetos. Atualmente a profissão é regida pela lei $8.662 / 93^{5}$ que estabelece suas competências e atribuições. Vale lembrar que dentre os princípios fundamentais do Assistente Social está o $5^{\circ}$ que trata do "posicionamento em favor da equidade e justiça social, que assegure universalidade de acesso aos bens e serviços relativos aos programas e políticas sociais, bem como sua gestão democrática" (BARROCO; TERRA, 2012, p. 127). Neste sentido, passou-se a buscar uma intervenção junto à população em situação de rua através de criações cotidianas e de resistências, tendo como objeto central essa população na cidade do Rio Grande diante o difícil acesso que os mesmos encontram nos dispositivos de saúde, haja vista a invisibilidade deste grupo.

Os Consultórios de Rua instituídos pela Política Nacional de Atenção Básica (PNAB) são formados por equipes multiprofissionais (Médicos, Enfermeiros, técnicos de Enfermagem e de saúde bucal, Assistentes Sociais, Psicólogos, Terapeutas ocupacionais, Agente Social) e prestam atenção integral à saúde de uma referida população em situação de rua in loco. As atividades são realizadas de forma itinerante desenvolvendo ações compartilhadas e integradas às Unidades Básicas de Saúde (UBS).

Sendo a atenção básica um nível prioritário ao fortalecimento do cuidado e à criação de vínculos na rede de saúde, pode-se buscar na gestão uma modalidade de atendimento que também atenda às necessidades dessa população. Diante dessa problemática, entende-se a necessidade de pesquisar as causas das doenças que acometem essa população em situação de rua para que possam ser tratadas diretamente no local onde essas pessoas vivem no momento, isto é, as ruas em seus diversos espaços e equipamentos urbanos de convivências. Espera-se, com esse artigo, mostrar a necessidade que existe em estabelecer um consultório de rua na cidade do Rio Grande - RS como mais um dispositivo de assistência à saúde da população, mas também como auxílio no trabalho realizado pelo Serviço Social em busca de garantir os direitos da população em situação de rua.

\footnotetext{
${ }^{5}$ Código de Ética Profissional do/a Assistente Social (BRASIL, 1993).
} 


\section{O Consultório de Rua: Do contexto histórico a nova modalidade}

O primeiro Consultório de Rua - CR surge em 1999, em Salvador, na Bahia. Um projeto-piloto criado em decorrência da problemática de crianças e adolescente que se encontravam na rua e sob uso problemático de drogas. A experiência foi do Centro de Estudo e Terapia do Abuso de Drogas. Em maio de 2004, um CR foi implantado no primeiro Centro de Atenção Psicossocial para atendimento em álcool e outras drogas (CAPS/AD) de Salvador, estruturando o modelo assistencial dessa unidade. Em 2009, o Ministério da Saúde (MS) propôs que o CR se tornasse uma das estratégias do Plano Emergencial de Ampliação de Acesso ao Tratamento em álcool e outras drogas, sendo incluído, em 2010, no Plano Integrado Nacional de Enfrentamento ao Crack com o objetivo de ampliar o acesso aos serviços assistenciais e qualificar o atendimento oferecido às pessoas que usam crack, álcool e outras drogas por intermédio de ações de saúde na rua.

Tal proposta procurou ampliar o acesso da população em situação de rua ao Sistema Único de Saúde (SUS) e ofertar, de maneira mais oportuna, atenção integral à saúde a esta população por meio das equipes e serviços da atenção básica. Outra experiência brasileira na base dos CR foram os Programas Saúde de Família sem Domicílio (PSF), mais tarde Equipe de Saúde da Família para População em Situação de Rua (ESF Pop Rua). Criando-se a partir de 2004, o PSF sem Domicílio, de Porto Alegre, seguido das ESF sem Domicílio de Belo Horizonte, de São Paulo e a ESF Pop Rua do Rio De Janeiro.

O PSF Sem Domicílio estava voltado para a População em situação de rua, com o atendimento de forma itinerante, como parte da rede de Atenção Básica à Saúde e do Programa de Atenção Integral à População Adulta de Rua, da área de assistência social, abordando moradores de rua, identificando as causas da sua situação, acionando os diversos setores que podem auxiliar na busca por vínculos familiar e ocupação. Para além do atendimento visando à promoção da saúde com tratamento e exames clínicos, hoje, as ESF Sem Domicílio para População em Situação de Rua funcionam como "Consultório na Rua" que é "uma prática de saúde que se propõe a atuar em contextos de risco psicossocial" (OLIVEIRA, 2009, p. 18).

Para o Ministério da Saúde, em uma das versões normativas introdutórias da modelagem de atendimento em consultório de rua, os mesmos "constituem uma modalidade de atendimento extramuros dirigida aos usuários de drogas que vivem em condições de maior vulnerabilidade social e distanciados da rede de serviço de saúde e intersetorial” (BRASIL, 2011). Para o desenvolvimento de suas atividades, necessita de um veículo de transporte de 
estilo micro-ônibus "multiuso", de modo que possa ser usado para o deslocamento da equipe multiprofissionais e transporte dos materiais necessários à realização das ações (BRASIL, 2010). Em Belo Horizonte, por exemplo, a Secretaria Municipal de Desenvolvimento Social assume a agenda política de ações voltadas a essa parcela da população em 1993, por meio do Programa de População em Situação de Rua - PSR, e fomenta a realização do Fórum da População em Situação de Rua.

A partir das constatações deste Fórum foi proposto e realizado um censo específico para população em situação de rua que reorientou a conformação dos serviços de saúde dirigidos a ela. Nesse contexto, percebeu-se que o processo de trabalho das equipes de Saúde da Família implantadas, caracterizado pela responsabilização por uma área geográfica fixa e uma população adstrita não era apropriado para incluir os moradores de rua, pela sua característica migratória, o que gerava uma exclusão desta população da rede assistencial.

Assim, em 2002, a Secretaria Municipal de Saúde de Belo Horizonte implanta a primeira equipe de Saúde da Família - eSF específica e exclusiva para o atendimento da PSR, sem território de abrangência fixo, que passa a ser o equipamento de Saúde de referência para essa população, e assume a vocação de matriciar as demais eSF do município na sensibilização do cuidado às PSR eventualmente presente nos territórios dessa forma transversal (BRASIL, 2011).

O termo "população em situação de rua" - PSR expressa mais a situação do sujeito em relação à rua e não apenas como ausência de casa. O Ministério do Desenvolvimento Social e Combate à Fome - MDSCF entende a população em situação de rua como "grupo populacional heterogêneo constituído por pessoas que possuem em comum a garantia da sobrevivência por meio de atividades produtivas desenvolvidas nas ruas, os vínculos familiares interrompidos ou fragilizados, e a não referência de moradia regular" (BRASIL, 2010)

O Consultório de Rua visa substituir o modelo tradicional de atendimento sendo equipes de profissionais onde os atendimentos são de forma itinerante com atendimento in loco, onde o público para quem se apresenta a necessidade e a atuação do Consultório de Rua é desafiador e complexo, incluindo a dupla exclusão de estar em situação de rua e ser usuário de drogas. Apesar dessa modalidade de clínica ainda ser nova pode vir a melhorar o atendimento da população em situação de rua no âmbito da saúde.

A Política Nacional de Atenção Básica - PNAB, através da Portaria n 2.488, de 21 de outubro de 2011, caracteriza a atenção básica como um conjunto de ações, no âmbito individual e coletivo, que abrange a promoção e a proteção da saúde, a prevenção de agravos, 
o diagnóstico, o tratamento, a reabilitação, e a redução de danos e a manutenção de saúde, com o objetivo de desenvolver uma atenção integral que impacte na situação de saúde e autonomia das pessoas e nos determinantes e condicionantes de saúde das coletividades. Neste sentido, a Estratégia Saúde da Família - ESF busca reorganizar as ações de Atenção Básica no Brasil. A iniciativa favorece uma reorientação do processo de trabalho com maior potencial de aprofundar os princípios, diretrizes e fundamentos da atenção básica; de ampliar a resolutividade e o impacto na situação das pessoas e coletividades.

Sendo assim, o Ministério da Saúde, ao eleger como modelo a criação de uma política de saúde para população em situação de rua com a possibilidade de acesso no atendimento do SUS, prevê a implantação do Consultório de Rua. No quadro 1, apresenta-se alguns municípios já contemplados com o Consultório de Rua:

Quadro 01 - Consultórios de rua já existentes no Brasil

- Maceió/AL- Projeto "Fique na Boa"

- Manaus/AM- Projeto "Renascer: um novo modelo de atendimento"

- Salvador/BA- Projeto "Capitães da Areia: Trabalhando na rua para construir projetos de vida no Centro Histórico de Salvador".

- Fortaleza/CE- Projeto Consultório de Rua e Redução de Danos: atenção integral ao usuário de álcool e outras drogas.

- Brasília/DF- Núcleo de Apoio aos Usuários de Álcool e outras drogas.

- Uberlândia/MG- Projeto "Na rua: oficinas itinerantes e redução de danos".

- Belém/PA- Projeto "Da Rua para Cidadania".

- João Pessoa/PB- Projeto "Estamos aqui...E aí?"

- Curitiba/PR- Projeto "Consultório de Rua de Curitiba".

- Recife/PE- Projeto "Consultório de Rua: reduzindo danos e saciando os apetites da alma".

- Niterói/RJ- Projeto" Tá na Pista”.

- Rio de Janeiro/RJ- Projeto "Consultório de rua na área".

- São Bernardo do Campo/SP- Projeto "Consultório de Rua reduzindo danos e ampliando acesso".

- Guarulhos/SP- Projeto "Consultório de Rua- Guarulhos".

Fonte: Elaborado pelos autores.

Este é um novo modelo de atendimento sendo uma unidade móvel que presta atenção integral à saúde da população de rua in loco, formado por equipes multiprofissionais e com atividades itinerantes desenvolvendo ações compartilhadas e integradas com as Unidades Básicas de Saúde - UBS, os Centro de Atendimento Psicossocial - CAPS, com os serviços de 
Urgência e Emergência de acordo com a necessidade do usuário. Os problemas de saúde por exemplo, demandados pela PSR têm origem em situações complexas, cujas respostas necessitam de intervenções articuladas entre gestores, profissionais de saúde e com diversos outros setores. Nesse contexto, todas as variáveis envolvidas no uso e tráfico de drogas, a dificuldades de prevenção de certos agravos transmissíveis (como ISTs ${ }^{6}$, dengue, leptospirose, tuberculose, dermatoses) e agravos em saúde mental e a rupturas de vínculos na relação familiar são cotidianos a serem enfrentados pela equipe do Consultório de Rua.

A rua cria condições extremamente adversas para a saúde das pessoas nesta situação, ainda que a maioria da sociedade enfrente essa problemática no caso deles a dificuldade de acesso é ainda maior. Por encontrarem dificuldade para o acesso, a grande maioria busca estratégias para o tratamento de saúde e esses grupos têm particularidades nas situações e doenças que possuem, já que há diversos fatores para o aparecimento das doenças nessa população, tais como a constante exposição ao sol, chuva e/ou frio. As pessoas em situação de rua consistem em um grupo específico da população e reflete a realidade de uma triste situação de saúde onde a precariedade de alimentação e de higiene facilita o aparecimento de várias doenças.

A desnutrição, o alcoolismo, o estresse constante de viver na denominada marginalidade são fatores decisivos para o adoecimento. Além disso, em sua grande maioria as pessoas em situação de rua sofrem com preconceito quando chegam às unidades de atendimento em más condições de higiene. Também há dificuldades constantes para assistência nos dispositivos de saúde, como por exemplo a falta de acompanhante em atendimento ou internação, prescrição de remédios inacessíveis, a falta de vagas em psiquiatrias e programas que os ajudem na dependência química - caso desejado e o difícil acesso para marcação de consultas especializadas, etc.

\subsection{A importância do exercício profissional do Serviço Social para a população em situação de rua}

I - elaborar, implementar, executar e avaliar políticas sociais junto a órgãos da administração pública, direta ou indireta, empresas, entidades e organizações populares;

II - elaborar, coordenar, executar e avaliar planos, programas e projetos que sejam do âmbito de atuação do Serviço Social com participação da sociedade civil; (CONSELHO FEDERAL DE SERVIÇO SOCIAL, 1993, p. 36-37).

\footnotetext{
${ }^{6}$ Infecções Sexualmente Transmissíveis.
} 
O assistente social é o agente formulador das estratégias necessárias para a elaboração, execução, planejamento e avaliação de políticas públicas, bem como a assessoria a movimentos sociais populares, dentre outros. Visto que "pode impulsionar formas democráticas na gestão de políticas e programas, socializar informações, alargar os canais que dão voz e poder decisório à sociedade civil, permitindo ampliar sua possibilidade de ingerência na coisa pública (IAMAMOTO, 2011, p. 79). Desse modo,

[...] a intervenção do Serviço Social com as pessoas em situação de rua busca amenizar as necessidades humanas primordiais para a dignidade do assistido, com vistas a realizar um trabalho articulado em rede para a garantia de direitos desta população. Dessa maneira, o Serviço Social se esforça para orientar e implementar condições humanas no exercício de sua profissão (SIQUEIRA; AMARAL, 2018, p. 25).

Com o passar dos anos, o assistente social tem se destacado como profissional qualificado para elaborar e executar políticas de bem-estar social, cabendo ao mesmo promover uma melhor inserção socioeconômica de indivíduos, famílias e grupos nas sociedades em que vivem, buscando nos próprios participantes a solução ou a minimização dos problemas sociais que os afetam. Percebemos a assistência social como um conjunto de ações que visam atender as mais variadas demandas sociais, desmitificando-se e se afastando da concepção de assistencialismo, caridade ou benevolência, que outrora era carregado, transportando-se para a categoria de direitos como juramentou a Constituição 1988 que a amparou sob o tripé da Seguridade Social. Queremos dizer com isso que a política de Assistência Social vem impactando "diretamente o cotidiano profissional, tencionando as dimensões das competências e atribuições privativas do assistente social que postula um profissional crítico vinculado às demandas coletivas de usuários ao acesso aos direitos, e as demandas institucionais" (SILVA, 2012, p. 156).

O conhecimento deste profissional está baseado nas técnicas adquiridas ao longo do seu processo de formação, fazendo com que os indivíduos contemplados se tornem mais independentes, seguros e conscientes das suas próprias capacidades e atitudes, visto que;

[...] as relações sociais de dominação se aperfeiçoaram e se refinaram ao ponto de o próprio cidadão não perceber que deixou de ser cidadão: ele é apenas usuário servil dos serviços e benefícios do Estado de Bem-Estar Social. Ele conquistou os direitos sociais, mas perdeu sua condição de sujeito político. Os cidadãos só aparecem nos discursos da social democracia, na prática eles não existem (CARVAHO; NETTO, 2011, p. 47). 
Sendo o objetivo desta profissão uma efetiva luta contra as desigualdades sociais, as degradações das condições de vida e das diversas faces da violência em nossa sociedade, exige-se uma atuação crítica e competência teórica dos assistentes sociais de modo que possam desmistificar o cotidiano e suas relações pautadas pela sociedade capitalista, buscando construir estratégias que superem os limites impostos à cidadania. Com base nisso, torna-se necessário uma postura ética, crítica e interventiva para que se conheça as diretrizes e bases que regem a profissão, atendendo aos usuários da melhor forma possível, prestando-lhe orientações, defendendo seus direitos, sejam eles civis, sociais ou políticos, mas sempre enfocando o coletivo.

Uma vez que a questão social é o instrumento principal de trabalho do assistente social, a compreensão relativa à questão social e a sociedade brasileira, resguardando suas características históricas particulares é encargo do assistente social, visto que "a força da prática social está no desenvolvimento do processo aberto, mobilizador de relações, reflexões e ação intergrupos. É a ação conjugada de um corpo social múltiplo e expressivo que introduz efeitos transformadores a nível do coletivo" (CARVAHO; NETTO, 2011, p. 57).

Para Paulo Freire,

No momento em que um assistente social, por exemplo, se reconhece como "o agente da mudança", dificilmente perceberá esta obviedade: que, se seu empenho é realmente educativo libertador, os homens com quem trabalha não podem ser objetos de sua ação. São, ao contrário, tão agentes da mudança quanto ele (FREIRE, 2015, p.53, grifo nossos).

O profissional de Serviço Social desenvolve diversas atividades, como acolhimento, orientações diversas, encaminhamentos para diversos setores, realização de contatos e visitas institucionais; desenvolve trabalho de articulação com a rede e demais setores, promoção de ações de educação em saúde, grupo temático, ações de redução de danos, participação em reuniões, construção de relatórios, entre outros. Esta compreensão abrange as relações Estadosociedade, os projetos políticos, as políticas sociais, as classes sociais e suas representações culturais e os movimentos sociais. O assistente social que atua no Consultório de Rua - por exemplo, tem que estar disposto a encarar um cotidiano muito específico e dinâmico, já que a rotina de trabalho se baseia na busca ativa dos usuários que serão atendidos, ou seja, são os profissionais que saem em busca da população em praças, casas e prédios abandonados, rodoviárias e etc.

\subsection{O Consultório de Rua na cidade de Rio Grande - RS}


A cidade de Rio Grande apresenta números significantes tratando-se de indivíduos em situação de rua. Com base nos dados do Cadastro Único para Programas Sociais - CADÚnico (2014) do município, existem cerca de 89 pessoas vivendo nas ruas, sendo 80 delas homens e 9 mulheres, com média de idade entre 30 e 40 anos. Infelizmente, não foi possível ter acesso aos dados de 2015, mas sabe-se que esses números aumentaram consideravelmente nesse ano.

A maioria das pessoas em situação de rua em Rio Grande se agrupa em praças e rodoviárias, catando materiais recicláveis para vender, tendo isso como única fonte de renda. Outra situação que chama atenção e vem se tornando cada vez mais frequente, é o número de moradores de rua, dependentes químicos, que se reúnem em grupos as margens de uma conhecida avenida do território municipal. Diariamente, observar-se grupos de usuários de crack, dormindo de baixo de árvores nessa localização, e durante a noite, mulheres na categoria de profissional de sexo na localidade.

Por conta dessa realidade na cidade, e por sua expansão, houve um aumento significativo no número de pessoas em situação de rua, dando entrada nos hospitais das cidades. Ao longo de visitações ao Hospital Universitário - HU de Rio Grande, foi possível observar números significativos de internações de indivíduos moradores de rua, internados principalmente por conta de Tuberculose, Sífilis, e complicações relacionadas à AIDS.

Legitimando as observações feitas no Hospital e ao longo dos dias, ao andar pelas ruas de Rio Grande, é possível observar o crescimento da população de rua e das doenças que os acometem a partir dos dados cedidos pelo Núcleo da Vigilância Epidemiológica de Rio Grande - RS, conforme quadro 2:

Quadro 2 - Doenças que acometem a população de rua na cidade de Rio Grande - RS

\begin{tabular}{|l|l|l|}
\hline Agravo & Ano de 2013 & Ano de 2014 \\
\hline Sífilis Adquirida & 101 & 305 \\
\hline Sífilis Congênita & 31 & 35 \\
\hline Sífilis Gestante & 60 & 66 \\
\hline AIDS Adulto & 103 & 325 \\
\hline AIDS Criança & 01 & 2 \\
\hline Tuberculose & 186 & 244 \\
\hline
\end{tabular}

Fonte: Dados cedidos dia 11/06/2015 pela Vigilância Epidemiológica Municipal à autora do presente artigo. 
A Portaria 3.088 de 2011 garante em seu texto a implementação de Consultórios de Rua em cidades onde hajam indivíduos em situação de rua, como dispositivo de assistência e garantia de atendimento a essas pessoas. A cidade de Rio Grande já conta com estruturas de atendimento na área de saúde mental (Conviver) e na área de dependência química (CAPS $\mathrm{AD})$, porém em ambos os casos o cidadão precisa se locomover até esses locais, o que muitas vezes serve como empecilho à sua procura. Buscando um controle acerca da situação encontrada em Rio grande, e dessa forma possibilitando o acompanhamento e suporte às pessoas em situação de rua na cidade, torna-se primordial a instalação de um consultório de rua.

"A precariedade e insalubridade das ruas, culminando em exposição e riscos cumulativos requerem intervenções e formas de tratamento orientadas, segundo a sua especificidade, desafiando os conceitos gerais de universalidade" (VARANDA; ADORNO, 2004, p. 56). Entendendo os números de Rio Grande, relativamente baixos se comparados à outras cidades, a implementação de tal dispositivo nesse momento aumentaria as chances de dar suporte e acompanhamento a esses indivíduos, tendo maiores e melhores resultados na tentativa de estabelecer uma melhor qualidade de vida aos mesmos e controle no que diz respeito às doenças que se desenvolvem nesses grupos.

\section{Considerações finais}

Pode-se concluir que, apesar do Consultório de Rua ser um dispositivo na área da saúde, ele ainda se estabelece como uma estrutura importante na área de Serviço Social e tem o assistente social como peça chave de seu funcionamento. Dentro dessa estratégia, o assistente social atua em especial como agente de mudança em conjunto com os usuários, levando pessoas em situação de rua até o dispositivo de atendimento, onde os profissionais de saúde farão seu trabalho. A implantação de um consultório de rua proporciona um atendimento direcionado à necessidade e à demanda dos indivíduos em situação de rua, fazendo com que os mesmos sejam atendidos, levando em consideração suas situações. Tal dispositivo de atendimento à saúde, aliado com outros dispositivos de atendimento às pessoas em situação de rua, podem aumentar a qualidade de vida dos mesmos e, consequentemente, podem trazer um reingresso dessas pessoas à sociedade de modo mais rápido.

A implementação de um consultório de rua em Rio Grande pode amenizar fortemente a situação que encontramos hoje, considerando o crescimento rápido da população de rua na cidade. Prestar atendimento a essas pessoas, tratando problemas de saúde precocemente, traz resultados positivos nas demais áreas envolvidas na busca de melhores condições ao morador 
de rua. Outro aspecto importante na instalação desse dispositivo na cidade é fazê-lo num momento em que a população de rua ainda se faz em números pequenos, se comparados com o número de habitantes na cidade.

Dessa forma, com uma demanda razoavelmente pequena, é possível trabalhar não apenas a melhoria na qualidade de vida dos moradores de rua, mas também através do assistente social, buscar sua reinserção social e na própria unidade familiar - caso desejado pelo usuário. Para que haja o pleno atendimento através desse dispositivo, o papel do assistente social é muito importante, levantando dados, apontando situações de necessária intervenção dos profissionais de saúde e levando o "morador de rua" até esse atendimento. Por essa razão, a cooperação entre profissionais da saúde e do serviço social se faz indispensável para o sucesso no funcionamento de um consultório de rua em qualquer localidade. Sua implementação na cidade, além de promover avanços no cumprimento dos direitos dos cidadãos de rua, ainda pode promover a prevenção do aumento de diversas doenças.

\section{Referências}

BARROCO, Maria Lucia; TERRA, Sylvia Helena. O código de ética do/a assistente social comentado. São Paulo: Cortez, 2012.

BRASIL. Lei no 8.662, de 7 de junho de 1993. Dispõe sobre a profissão de Assistente Social e dá outras providências. Diário Oficial da União, Brasília, DF, 08 jun. 1993.

BRASIL. Ministério do Desenvolvimento e Combate à Fome. Rua aprendendo a contar: Pesquisa Nacional sobre População em Situação de Rua. 2010.

BRASIL. Ministério da Saúde. Manual sobre o cuidado à saúde junto à população em situação de rua. Brasília: MS, 2011.

CARVALHO, M. C. B; NETTO, J. P. O conhecimento da vida cotidiana: base necessária à prática social. In: CARVALHO, M. C. B; NETTO, J. P. Cotidiano: conhecimento e crítica. 9. ed. São Paulo: Cortez, 2011.

FREIRE, Paulo. Extensão ou comunicação? 17. ed. São Paulo: Paz e Terra, 2015.

IAMAMOTO, Marilda Villela. Serviço Social em Tempo de Capital Fetiche: Capital Financeiro, trabalho e questão social. $6^{\mathrm{a}}$ ed. São Paulo: Cortez, 2011.

OLIVEIRA, Mírian Gracie Plena Nunes de. Consultório de Rua: relato de uma experiência. (Dissertação). Salvador: Universidade Federal da Bahia, Instituto de Saúde Coletiva. 2009. 
SILVA, J. A. F. Serviço Social e Sistema Único de Assistência Social (SUAS): reflexões sobre o trabalho profissional. Ser Social, Brasília, v. 14, n. 30, p. 155-189, jan./jun. 2012. Disponível em: 〈https://periodicos.unb.br/index.php/SER_Social/article/view/12826>. Acesso em: 3 abr. 2020.

SIQUEIRA, I. F. S. ; AMARAL, Marcel Jardim . O Assistente Social e a (in)visibilidade da população em situação de rua na cidade de Rio Grande - RS. In: Laís Braga Costa; Bibiana da Roza Caporal. (Org.). Desafios do mundo contemporâneo. 1. ed. São Paulo: Pimenta Cultural, 2018, v. I, p. 23-33.

VARANDA, Walter; ADORNO, Rubens de Camargo Ferreira. Descartáveis urbanos: discutindo a complexidade da população de rua e o desafio para políticas de saúde. Saúde soc., São Paulo, v. 13, n. 1, p. 56-69, abr. 2004. Disponível em: http://www.scielo.br/scielo .php?script=sci_arttext\&pid=S0104-12902004000100007\&lng=en\&nrm=iso. Acesso em: 12 mar. 2020. 